\title{
The role of infectious agents in urogenital cancers
}

\author{
Kenneth Alibek ${ }^{1,2}$, Nargis Karatayeva ${ }^{1 *}$ and Ildar Bekniyazov ${ }^{1}$
}

\begin{abstract}
Since the late 1990s, infectious agents have been thought to play a role in the pathogenesis of approximately $15 \%$ of cancers. It is now widely accepted that infection of stomach tissue with the bacteria Helicobacter pylori is an important cause of stomach adenocarcinoma. In addition, oncogenic viruses, such as papilloma viruses, herpes viruses, and hepadnaviruses are strongly associated with increased risk of cervical cancer, lymphomas, liver cancer, amongst others. However, in the scientific community the percentage of cancers caused by pathogens is believed to be far higher than $15 \%$. A significant volume of data collected to date show an association between infectious agents and urogenital cancers. These agents include Chlamydia trachomatis, Neisseria gonorrhoea, Mycoplasma genitalium and certain viruses that have been implicated in ovarian cancer. Other pathogens include the hepatitis $C$ and Epstein-Barr viruses, which are potentially involved in kidney cancer. In addition, infections with Schistosoma haematobium, the human papillomavirus, and human polyomaviruses are strongly associated with an increased risk of urinary bladder cancer. This article reviews publications available to date on the role of infectious agents in urogenital cancers. A greater understanding of the role of such agents could aid the identification of novel methods of urogenital cancer treatment.

Keywords: Urogenital cancers, Ovarian cancer, Cervical cancer, Bladder cancer, Kidney cancer, Chlamydia trachomatis, Neisseria gonorrhea, Mycoplasma genitalium, Schistosoma haematobium, HPV, Epstein-Barr, CMV, Human polyomaviruses
\end{abstract}

Urogenital tract cancers including ovarian, cervical, kidney and bladder carcinomas are among the most common and lethal cancers worldwide. Numerous factors could be involved in urogenital cancer development, including genetic predisposition, lifestyle, and infectious agents. Approximately $15 \%$ of cancers worldwide are caused by microorganisms [1], but growing evidence indicates this number might be much higher. This article reviews literature available to date on the role of microorganisms in urogenital tract cancers. A greater understanding of the function of such microorganisms in promoting carcinogenesis is required to aid identification of novel strategies for cancer treatment.

\section{Ovarian cancer}

Ovarian carcinoma is a common human tumor of the genital tract and one of the most lethal cancers worldwide [2]. In 2008, ovarian carcinoma was the 2nd most

\footnotetext{
* Correspondence: nkaratayeva@nu.edu.kz

'Nazarbayev University, 53 Kabanbay Batyr Avenue, Astana 010000, Kazakhstan

Full list of author information is available at the end of the article
}

lethal gynecological cancer [3]. The molecular events occurring during early stages of ovarian carcinogenesis are not well understood due to the absence of symptoms in patients and the site of origins of neoplastic lesions. Most patients are diagnosed with ovarian cancer when the tumor is at an advanced stage and has metastasized to the peritoneum. The prognosis of ovarian cancer is therefore poor. Moreover, ovarian cancers rapidly develop resistance to cytotoxic drugs [4]. Piek et al. [5] list three possible routes of ovarian carcinogenesis: ovarian surface epithelial tissue, embryologic Mullerian ducts, and the inner surface epithelium of the Fallopian tube.

Most aggressive ovarian carcinomas arise from ovarian surface epithelium (OSE) cells and account for about $60 \%$ of all ovarian carcinomas. Non-epithelial ovarian tumors arising from oocytes and sex cord stromal cells usually remain benign. Thus, ovarian epithelial tumors receive greater attention, and multiple studies are currently underway to determine the origins of neoplastic lesions in the OSE and understand the early molecular events of the disease. Two broadly accepted theories of OSE carcinogenesis are incessant ovulation and 
gonadotropin. The incessant ovulation theory suggests the epithelium may be more apt to mutate with each ovulation and failure to break the cycle, as in pregnancy, increases the chance of mutation. The gonadotropin theory suggests elevated gonadotropin levels trigger proliferation of the ovarian epithelium, with subsequent malignant transformation. Epidemiological data available to date do not provide sufficient evidence for either theory [6,7].

In a third theory, Ness and Cottreau [8] suggested that inflammatory-like processes, occurring during ovulation and mediated by gonadotropins, underlie higher cancer risks associated with ovulation and gonadotropin stimulation. This inflammation theory is supported by several epidemiological studies focused on mechanisms that did not affect hormone levels and ovulation, including effects of asbestos and talc exposure, prophylactic hysterectomy and tubal ligation, pelvic inflammatory disease and endometriosis [9-17]. It was previously established that chronic inflammation, a response of the organism to pathogens or irritants, could lead to neoplastic transformation of inflamed tissues due to host defense mechanisms and their products, which were thought to have antimicrobial properties [18]. During inflammation, mutagenic substances such as reactive oxygen and nitrogen species are released by neutrophils and macrophages and play a crucial role in promoting carcinogenesis. These species can directly damage DNA by oxidation and nitration, and modify cancer-related proteins [19]. In combination with elevated levels of cell proliferation for repair of damaged tissue, these changes create favorable conditions for increased transformation.

Apoptosis is another critical cellular mechanism that eliminates damaged or unwanted cells by directing them to undergo programmed cell death. It is also a vital process that contributes significantly to the protection from tumor formation. Thus inhibition of apoptosis increases the risk of malignancy, and it was found that cells infected with Chlamydia trachomatis (C.trachomatis) and human papillomavirus (HPV) are resistant to apoptosis $[20,21]$.

Various microorganisms involved in sexually transmitted diseases, including C.trachomatis and Mycoplasma genitalium (M.genitalium), have been associated with a higher risk for ovarian cancer [22,23]. These pathogens cause chronic and asymptomatic infection, increasing the risk of neoplastic transformation of the OSE. These pathogens are also associated with pelvic inflammatory disease (PID) and tubal infertility factor (TIF), suggesting they can traverse from the lower to upper genital tract infecting and causing persistent inflammation in the Fallopian tubes and ovaries. These associations indicate that more attention should be paid to the role of these pathogens in ovarian cancer.
C.trachomatis is the most prevalent infection of the genital tract in women worldwide, and the disease is usually asymptomatic [24]. It is possible to suggest that cells infected by chlamydia have a much higher risk of neoplastic transformation because the pathogen is able to cause persistent inflammation and hence tissue damage, and has an antiapoptotic activity on infected cells [21]. Chlamydia is an obligatory intracellular pathogen and can replicate only inside a cytoplasmic vacuole (phagosome) of the host cell. It is able to cause chronic asymptomatic infection due to the fact that it can evade the host immune response by preventing the fusion of the phagosome with a lysosome by an unknown mechanism [25], by inhibiting expression of the host cell's major histocompatibility complex antigen [26-29], and by blocking pathways to apoptosis. In the study by Greene et al. [16], serovars of C. trachomatis and C.psittaci were analyzed and inhibition of apoptosis of infected cells in cultures was observed. Moreover, the authors observed that DNA synthesis was unaffected in infected cells and infected cells could undergo mitosis at any stage of infection which also increases the risk of malignant transformation of infected cells. The mechanisms and key players involved in blocking apoptosis in infected cells require further investigation. Some studies $[30,31]$ suggest that chlamydia heat shock protein (a major cause of persistent inflammation) might have antiapoptotic activity. Serum antibodies to this protein were elevated in women with TFI [32]. Cooper et al. [33] observed that chlamydia also has a cytotoxic effect on cells promoting loss of microvilli and cell junctions, likely by producing a toxin (homologous to large clostridial cytotoxin) [34]. Loss of cell adhesion resulting from the loss of cell junctions induces selection of preneoplastic cells. It remains to be determined whether other bacterial toxins or proteins that can affect the host cell's DNA directly.

M.genitalium is well associated with PID and TFI, and could also cause chronic asymptomatic infection in the upper genital tract. M.genitalium might increase the risk of neoplastic transformation of tubal and ovarian tissue. However, Idahl et al. [23] did not find an association between M.genitalium antibodies and ovarian tumors. Nonetheless, prolonged infection could cause morphological changes in mammalian host cells. A study by Baczynska et al. [35], demonstrated that Mycoplasma hominis (M.hominis) and M.genitalium caused swelling of the tubal epithelial cilia through production of a toxin or metabolism products - hydrogen peroxide and superoxide radicals. This is consistent with finding of recent studies suggesting some serous ovarian carcinomas (the most aggressive ovarian carcinoma) can originate from the Fallopian tube epithelium $[5,36]$. Another study by Namiki et al. [37] demonstrated that prolonged infection 
of benign human prostate cells in culture with M.genitalium and Mycoplasma hyorhinis caused malignant transformation through an unknown mechanism.

Neisseria gonorrhea (N.gonorroea) is a facultative intracellular pathogen that attaches to the apical surface of the genital tract epithelium. Neisseria gonorrhea has not been associated with ovarian cancer so far. However, the attachment of the pathogen to the epithelium of the genital tract provokes various cell signaling events and alters expression of many cellular proteins, which might predispose them to malignant transformation. N.gonorrhoea alters cell cycle progression by reducing expression of cyclin B and arresting cells in the G1 phase of the cell cycle [38]. Löfmark et al. [39] investigated Me180 (cervical carcinoma cell line) and HEC-1-B (endometrial adenocarcinoma cell line) cells infected with $N$. gonorrhoea and examined their levels of amphiregulin expression. Amphiregulin is an epidermal growth factor receptor ligand, expressed in the G1 stage that promotes cellular growth and cell cycle progression. The role of amphiregulin in various cancers has been extensively investigated. Amphiregulin appears to contribute to tumorigenesis by promoting independent production of growth signals, limitless proliferation, tissue invasion and metastasis, angiogenesis, and resistance to apoptosis (reviewed in [40]). Amphiregulin was expressed at higher rates following infection in Me-180 and HEC-1-B cell lines. However, the effect of amphiregulin on OSE cells and the ability of N.gonorrhoea to cause their malignant transformation require elucidation.

A recent study by Shanmughapriya, et al. [41], showed HPV and cytomegalovirus (CMV) DNA were present in fresh ovarian carcinoma tissue samples in $40 \%$ and $50 \%$ of samples, respectively. The samples were collected from 39 women in total. The authors assumed that the HPV infection could arise from HPV-coated sperm that contact upper genital tract tissues. Ovarian CMV infections are quite rare and the authors therefore suggest that activation of the virus occurs during immunocompromised states that may occur following chemotherapy, radiotherapy, and metastatic disease. It was suggested that human cytomegalovirus is able to induce oncomodulation in infected cells, in other words the virus creates a more malignant phenotype of tumor cells by the action of its regulatory proteins and non-coding RNA which will affect their proliferation, invasion of other tissues, survival and other cellular properties [42]. However further investigation is necessary to determine whether ovaries are the primary site of CMV infection.

\section{Cervical cancer}

Cervical cancer arises in the cervix uteri and is the most prevalent gynaecological malignancy worldwide [2]. HPV infection with high-risk HPV (16 and 18) is one of the most common causes of cervical cancer [43], other pathogens like C.trachomatis [44] and Epstein-Barr virus [45-47] were also found to be implicated in cervical carcinoma acting either independently or as co-factors in predisposing cervical epithelial cells to malignancy. Other factors that increase the risk of developing cervical carcinoma are genetic predisposition, smoking, weakened immunity, life style.

HPV is a small DNA virus that infects various epithelial tissues, and two types of the virus, HPV 16 and 18, are responsible for $70 \%$ of cervical carcinomas [43]. The virus inserts itself into human DNA, producing proteins that cause neoplastic transformation of the cervical epithelial cells. The key players involved in this process are early proteins 6 and 7 (E6 and E7), which are produced by HPV 16 and HPV 18 respectively. The viral DNA does not disrupt any human genes; instead, protein products of the viral genes - E6 and E7 proteins bind to the human tumor-suppressor proteins $\mathrm{p} 53$ and $\mathrm{pRb}$, respectively, and inactivate them by promoting protein degradation (reviewed in [31]). Inactivation of these tumor-suppressors eventually leads to accumulation of mutations and onset of cancer. However, transient HPV infection is not sufficient to cause cervical neoplasia; it was previously observed that the infection could be cleared in most women $[48,49]$. The infection has to be persistent to cause transformation.

As some studies have shown, C.trachomatis increases the risk of HPV infection becoming persistent by increasing HPV's access to the basal epithelium due to microabrasions of the cervical epithelium or changing its characteristics, or by preventing efficient clearance of the viral infection [50,51]. Also a study by Lehtinen et al. [44] demonstrated that C.trachomatis infection was an independent risk factor for cervical neoplasia. This could be because the pathogen blocks pathways to apoptosis in infected cells while promoting their entry to the $S$ phase, causing chronic inflammation. Other sexually transmitted diseases could play a similar role to C.trachomatis, leading to persistence of HPV infection. The mechanisms involved in this process still need to be determined.

The correlation between Epstein-Barr virus (EBV) infection and uterine cervical cancer has been reported in several studies [45-47]. The role of EBV in cervical cancer was tested by examining the presence and expression of EBV genes in cervical carcinoma and normal cervical tissue. The EBV genome was present in 55\% (17 of 31) of carcinoma samples and in 26\% (9/35) of normal samples [45]. A later study used mRNA in situ hybridization to detect mRNA of EBV nuclear antigen 2 in tissue samples from patients with invasive uterine cervical cancer and cervical intraepithelial neoplasia [46]. The authors found EBV nuclear antigen-2 (EBNA2) mRNA in these samples; furthermore, they detected expression of EBNA 
leader protein $2 \mathrm{c}$ by using mRNA in situ hybridization and indirect immunofluorescent staining [47]. Another study demonstrated the significance of cervical coinfection with HPV 16 and EBV in uterine cervical cancer patients: all patients carried IgG-anti-VCA and IgG-anti-EBNA serum and more than 30\% (of 48 patients) were also infected with HPV 16 [52].

\section{Kidney cancer}

Kidney cancer includes renal cell carcinoma (RCC) and renal pelvis carcinoma, and it also includes Wilms tumor, a type of kidney cancer that usually develops in children under the age of 5 . According to the International Agency for Research on Cancer in 2008, the global incidence of kidney cancer was 273,518 cases ( $2.3 \%$ of all cancer cases) and mortality was at 116,368 cases (1.5\% of all cancer mortality cases) making RCC 11th most frequent cancer worldwide. Several studies have revealed an association between kidney cancer and viruses. The World Health Organization estimated that 130-170 million people are chronically infected with hepatitis $\mathrm{C}$ virus (HCV), a major cause of cirrhosis, liver failure, and hepatocellular carcinoma. A study by Gordon et al. [53] compared incidences of RCC between anti-HCV positive adults and an anti-HCV negative control group, and found that chronic infection with $\mathrm{HCV}$ was associated with an increased risk of RCC. In addition, the seroprevalence of $\mathrm{HCV}$ in patients with RCC who participated in the cohort study by Gordon et al. was higher than the overall seroprevalence of $\mathrm{HCV}$ in the United States (4.3\% and $1.6 \%$ respectively).

Interestingly, the results of study by Salehipoor et al. [54] suggested an association between high-risk types of HPV and RCC. In this study, nested PCR was used to detect HPV in 49 patients with clinical and histopathological diagnoses of RCC. Subsequently, $14.29 \%$ of RCC tissues tested positive for HPV, but no expression of EBV was detected in the control group. All of the detected HPV types were high-risk ones (type 16 in 3 and 18 in 4 patients).

In concordance with the above findings, results from several studies suggested the involvement of EBV in RCC pathogenesis. In a study by Shimakage et al. [55], EBV mRNA was detected in RCC and nephroblastoma by in situ hybridization. The expression of EBV was stronger in clear-cell type and papillary RCC than in chromophobe cell type RCC.

Urinary tract infection history was also shown to play a role in kidney cancer development, as Parker et al. [56] reported a positive association of urinary tract infection history with the risk of renal cell carcinoma development. Urinary tract infection history was also shown to play a role in kidney cancer development, as Parker et al. [56] reported a positive association between the risk of RCC development and a history of urinary tract infections in patients.

\section{Bladder cancer}

Urinary bladder cancer can be divided into distinct types, including transitional cell carcinoma (the most common), squamous cell carcinoma and adenocarcinoma. Bladder cancer is the 7th most common cancer among males and 17th most common malignancy in females. In 2008, bladder cancer was the 9th most common cancer globally [57].

Urinary forms of schistosomiasis that is caused by Schistosoma haematobium (S.haematobium) is an infection commonly associated with an increased risk for urinary bladder cancer. An association between schistosomiasis and urinary bladder cancer is particularly evident in Egypt, where schistosomiasis is endemic. The overall prevalence of S.haematobium infection in Egypt is $37-48 \%$ [58]. Urinary bladder cancer is the most common type of cancer in males, and 2nd most common in females, and accounts for nearly $3 \%$ of the total cancer incidence in Egypt (compared to the 5-7th most common cancer in males and 7-14th most common cancer in females in schistosoma-free countries) [58].

Studies conducted by the International Agency for Research on Cancer (IARC) [59] revealed that infections with S.haematobium predisposed patients to bladder cancer, in particular, squamous cell carcinoma. Individuals heavily infected with S.haematobium were more likely to develop bladder cancer, and at a younger age. Bedwani et al. [60] studied the relationship between the clinical history of schistosomiasis and risk for bladder cancer by analyzing data from case-control studies involving 190 bladder cancer patients and 187 control subjects with non-urinary tract conditions. The study showed that schistosomiasis was associated with an increased risk of bladder cancer and accounted for $16 \%$ of bladder cancer cases in that Egyptian population.

Urinary bladder cancer was also shown to be associated with viruses. For example, a meta-analysis [61] revealed that infections with high-risk HPV (HR-HPV) types, especially HPV16, might play a significant role in bladder carcinogenesis. Various studies led to the detection of HPV DNA in benign and malignant neoplasms of the bladder [62-65]. Barghi et al. [66] found HPV DNA in $36 \%$ of transitional-cell bladder cancer specimens. Moonen et al. [67] detected HPV DNA in 15\% of urinary bladder cancer patients, and HR-HPV DNA in $8 \%$ of patients (from a total of 107 patients). The number of specimens positive for HR-HPV DNA increased with the clinical progression of the disease, with HRHPV detected in $0 \%$ of Ta, $12.5 \%$ of $\mathrm{T} 1$, and $18.2 \%$ of T2-T4 stage bladder cancers. HPV16 and HPV18 DNA were detected in nearly $50 \%$ of urinary bladder dysplasia 
and carcinoma specimens when examined using in situ hybridization [68]. In another study, HPV16 genetic material was found in $40 \%$ of transitional bladder cancer specimens [69]. Despite the results of these studies, the IARC concluded that there is "inadequate evidence" to support a role of HPV in bladder carcinogenesis. The human polyomaviruses BKV and JCV establish persistent infections in humans and possess oncogenic and transforming potential in experimental animal models and cell cultures [54]. The presence of BKV and JCV were detected in urothelial carcinomas of the renal pelvis RCCs [69]. However, no definitive association between BKV and human cancers has been established to date [70,71]. Shen et al. [72], detected JCV DNA using nested PCR in $90.1 \%$ (30 out of 33) urothelial carcinoma tissue samples and in 100\% (5 out of 5) renal cell carcinoma samples. BKV DNA was detected in only one (3\%) urothelial carcinoma tissue sample. Geetha et al. [73], detected elevated levels of BKV large T antigen expression in a bladder carcinoma developed in a simultaneous kidney and pancreas transplant recipient. Such levels were not observed in non-neoplastic urothelium. Based on these findings, the authors suggested that BKV virus might function as an etiologic agent in the development of urinary bladder carcinoma.

\section{Conclusion}

A growing body of evidence indicates that some viruses, bacteria and even helminths might increase cancer risk by promoting general inflammation and subsequently affecting key cellular processes. However, the exact mechanisms by which the products of how pathogens promote or predispose cells to neoplastic transformation are unknown. One exception is HPV, which has been shown to induce carcinogenesis in cervical epithelial cells by inactivating tumor suppressor proteins. However, in cases of ovarian, kidney and bladder cancer we can only infer a role for infectious agents based on their associations with these cancers. More in-depth and mechanistic studies are required to understand the molecular mechanisms, by which infectious agents could promote carcinogenesis. Such studies could lead to identification of novel methods of urogenital cancer treatment.

\footnotetext{
Abbreviations

OSE: Ovarian surface epithelium; HPV: Human papillomavirus; PID: Pelvic inflammatory disease; TFI: Tubal factor infertility; CMV: Cytomegalovirus; EBV: Epstein-Barr virus; RCC: Renal cell carcinoma; HCV: Hepatitis C virus; IARC: International Agency for Research on Cancer; HR-HPV: High-risk human papillomavirus.
}

\section{Competing interests}

The authors declare that they have no competing interests.

\section{Authors' contributions}

KA, NK and IB performed literature research and composed the manuscript. All authors read and approved the final manuscript.

\section{Acknowledgements}

The authors wish to thank Dr. Charles Gilman for valuable comments. This project was funded by the Center for Energy Research at Nazarbayev University.

\section{Author details}

${ }^{1}$ Nazarbayev University, 53 Kabanbay Batyr Avenue, Astana 010000, Kazakhstan. ${ }^{2}$ Republican Scientific Center for Emergency Care, 3 Kerey and Zhanibek Khan Street, Astana 010000, Kazakhstan.

Received: 21 May 2012 Accepted: 20 November 2012

Published: 3 December 2012

\section{References}

1. Pisani P, Parkin DM, Muñoz N, Ferlay J: Cancer and infection: estimates of the attributable fraction in 1990. Cancer Epidemiol Biomarkers Prev 1997, 6(6):387-400.

2. Sankaranarayanan R, Ferlay J: Worldwide burden of gynaecological cancer: the size of the problem. Best Pract Res Clin Obstet Gynaecol 2006, 20(2):207-225.

3. Ferlay J, Shin HR, Bray F, Forman D, Mathers C, Parkin DM: Estimates of worldwide burden of cancer in 2008: GLOBOCAN 2008. Int I Cancer 2010, 127(12):2893-2917.

4. Weinberg RA: The rational treatment of cancer. In The biology of cancer. 1st edition. Edited by Garland Science. LLC: Taylor \& Francis Group; 2007:725-795.

5. Piek JM, van Diest PJ, Verheijen RH: Ovarian carcinogenesis: an alternative hypothesis. Adv Exp Med Bio 2008, 622:79-87.

6. Riman T, Nilsson S, Persson IR: Review of epidemiological evidence for reproductive and hormonal factors in relation to the risk of epithelial ovarian malignancies. Acta Obstet Gynecol Scand 2004, 83(9):783-795.

7. Lukanova A, Kaaks R: Endogenous hormones and ovarian cancer: epidemiology and current hypotheses. Cancer Epidemiol Biomarkers Prev 2005, 14(1):98-107.

8. Ness RB, Cottreau C: Possible role of ovarian epithelial inflammation in ovarian cancer. J Natl Cancer Inst 1999, 91(17):1459-1467. Review. PubMed PMID: 10469746.

9. Camargo MC, Stayner LT, Straif K, Reina M, Al-Alem U, Demers PA, Landrigan PJ: Occupational exposure to asbestos and ovarian cancer: a meta-analysis. Environ Health Perspect 2011, 119(9):1211-1217. Epub 2011 Jun 3.

10. Reid A, de Klerk N, Musk AW: Does exposure to asbestos cause ovarian cancer? A systematic literature review and meta-analysis. Cancer Epidemiol Biomarkers Prev 2011, 20(7):1287-1295. Epub 2011 May 24.

11. Munksgaard PS, Blaakaer J: The association between endometriosis and ovarian cancer: a review of histological, genetic and molecular alterations. Gynecol Oncol 2012, 124(1):164-169. Epub 2011 Oct 26.

12. Sainz de la Cuesta R, Eichhorn JH, Rice LW, Fuller AF Jr, Mikrui N, Goff BA: Histologic transformation of benign endometriosis to early epithelial ovarian cancer. Gynecol Oncol 1996, 60:238-244.

13. Jimbo H, Yoshikawa H, Onda T, Yasugi T, Sakamoto A, Taketani Y: Prevalence of ovarian endometriosis in epithelial ovarian cancer. Int $J$ Gynecol Obstet 1997, 59:245-250.

14. DePriest PD, Banks ER, Powell DE, van Nagell JR, Gallion Jr HH, Puls SE, et al: Endometrioid carcinoma of the ovary and endometriosis: the association in postmenopausal women. Gynecol Oncol 1992, 47:71-75.

15. Rice MS, Murphy MA, Tworoger SS: Tubal ligation, hysterectomy and ovarian cancer: a meta-analysis. J Ovarian Res. 2012, 5(1):13.

16. Shu XO, Brinton LA, Gao YT, Yuan JM: Population-based case-control study of ovarian cancer in Shanghai. Cancer Res 1989, 49:3670-3674.

17. Risch HA, Howe GR: Pelvic inflammatory disease and the risk of epithelial ovarian cancer. Cancer Epidemiol Biomarkers Prev 1995, 4:447-451.

18. Rakoff-Nahoum S: Why cancer and inflammation? Yale J Biol Med 2006, 79(3-4):123-130

19. Hussain SP, Hofseth LJ, Harris CC: Radical causes of cancer. Nat Rev Cancer 2003, 3(4):276-285.

20. Greene W, Xiao Y, Huang Y, McClarty G, Zhong G: Chlamydia-infected cells continue to undergo mitosis and resist induction of apoptosis. Infect Immun 2004, 72(1):451-460.

21. IARC Working Group on the Evaluation of Carcinogenic Risks to Humans: Human papillomaviruses. IARC Monogr Eval Carcinog Risks Hum 2007, 90:1-636. 
22. Paavonen J: Chlamydia trachomatis and cancer. Sex Transm Infect 2001, 77:154-156.

23. Idahl A, Lundin E, Jurstrand M, Kumlin U, Elgh F, Ohlson N, Ottander U: Chlamydia trachomatis and mycoplasma genitalium plasma antibodies in relation to epithelial ovarian tumors. Infect Dis Obstet Gynecol 2011, 2011:824627. Published online 2011 July 28.

24. Goering RV: Sexually transmitted diseases. In Mims' Medical Microbiology. 1st edition. Edited by Goering R, Dockrell H, Roitt I, Zuckerman M, Wakelin D.: Elsevier Limited; 2003:261-285.

25. Scidmore MA, Fischer ER, Hackstadt T: Restricted fusion of Chlamydia trachomatis vesicles with endocytic compartments during the initial stages of infection. Infect Immun 2003, 71(2):973-984.

26. Zhong GM, Reid RE, Brunham RC: Mapping antigenic sites on the major outer membrane protein of Chlamydia trachomatis with synthetic peptides. Infect Immun 1990, 58(5):1450-1455.

27. Zhong G, Fan T, Liu L: Chlamydia inhibits interferon gamma-inducible major histocompatibility complex class II expression by degradation of upstream stimulatory factor 1. J Exp Med 1999, 189(12):1931-1938.

28. Zhong G, Liu L, Fan T, Fan P, Ji H: Degradation of transcription factor RFX5 during the inhibition of both constitutive and interferon gammainducible major histocompatibility complex class I expression in chlamydia-infected cells. J Exp Med 2000, 191(9):1525-1534.

29. Zhong G, Fan P, Ji H, Dong F, Huang Y: Identification of a chlamydial protease-like activity factor responsible for the degradation of host transcription factors. J Exp Med 2001, 193(8):935-942.

30. Dean D, Powers VC: Persistent Chlamydia trachomatis infections resist apoptotic stimuli. Infect Immun 2001, 69(4):2442-2447.

31. Beatty WL, Byrne Gl, Morrison RP: Morphologic and antigenic characterization of interferon gamma-mediated persistent Chlamydia trachomatis infection in vitro. Proc Natl Acad Sci USA 1993, 90(9):3998-4002.

32. Hjelholt A, Christiansen G, Johannesson TG, Ingerslev HJ, Birkelund S: Tubal factor infertilityis associated with antibodies against Chlamydia trachomatis heat shock protein 60 (HSP60) but not human HSP60. Hum Reprod 2011, 26(8):2069-2076.

33. Cooper MD, Rapp J, Jeffery-Wiseman C, Barnes RC, Stephens DS: Chlamydia trachomatis infection of human fallopian tube organ cultures. $J$ Gen Microbiol 1990, 136(6):1109-1115.

34. Belland RJ, Scidmore MA, Crane DD, Hogan DM, Whitmire W, McClarty G, Caldwell HD: Chlamydia trachomatis cytotoxicity associated with complete and partial cytotoxin genes. Proc Natl Acad Sci USA 2001, 98(24):13984-13989.

35. Baczynska A, Funch P, Fedder J, Knudsen HJ, Birkelund S, Christiansen G: Morphology of human Fallopian tubes after infection with Mycoplasma genitalium and Mycoplasma hominis-in vitro organ culture study. Hum Reprod 2007, 22(4):968-979.

36. Jazaeri AA, Bryant JL, Park H, Li H, Dahiya N, Stoler MH, Ferriss JS, Dutta A: Molecular requirements for transformation of fallopian tube epithelial cells into serous carcinoma. Neoplasia 2011, 13(10):899-911.

37. Namiki K, Goodison S, Porvasnik S, Allan RW, Iczkowski KA, Urbanek C, Reyes L, Sakamoto N, Rosser CJ: Persistent exposure to Mycoplasma induces malignant transformation of human prostate cells. PLoS One 2009, 4(9):e6872.

38. Jones $A$, Jonsson $A B$, Aro $H$ : Neisseria gonorrhoeae infection causes a $G 1$ arrest in human epithelial cells. FASEB J 2007, 21(2):345-355.

39. Löfmark S, de Klerk N, Aro H: Neisseria gonorrhoeae infection induces altered amphiregulin processing and release. PLoS One 2011, 6(1):e16369.

40. Busser B, Sancey L, Brambilla E, Coll JL, Hurbin A: The multiple roles of amphiregulin in human cancer. Biochim Biophys Acta 2011, 1816(2):119-131.

41. Shanmughapriya S, Senthilkumar G, Vinodhini K, Das BC, Vasanthi N, Natarajaseenivasan K: Viral and bacterial aetiologies of epithelial ovarian cancer. Eur J Clin Microbiol Infect Dis 2012, [Epub ahead of print].

42. Michaelis M, Doerr HW, Cinatl J Jr: The story of human cytomegalovirus and cancer: increasing evidence and open questions. Neoplasia 2009, 11(1):1-9.

43. HPV and cancer. In National Cancer Institute. 2012 [online] Available at: http://www.cancer.gov/cancertopics/factsheet/Risk/HPV\#r5 [Accessed 17 September 2012].

44. Lehtinen M, Ault KA, Lyytikainen E, Dillner J, Garland SM, Ferris DG, Koutsky LA, Sings HL, Lu S, Haupt RM, Paavonen J, FUTURE I and II Study Group:
Chlamydia trachomatis infection and risk of cervical intraepithelial neoplasia. Sex Transm Infect 2011, 87(5):372-376.

45. Sasagawa T, Shimakage M, Nakamura M, Sakaike J, Ishikawa H, Inoue M: Epstein-Barr virus (EBV) genes expression in cervical intraepithelial neoplasia and invasive cervical cancer: a comparative study with human papillomavirus (HPV) infection. Hum Pathol 2000, 31(3):318-326.

46. Shimakage M, Sasagawa T: Detection of Epstein-Barr virus-determined nuclear antigen-2 mRNA by in situ hybridization. J Virol Methods 2001, 93(1-2):23-32.

47. Shimakage M, Harada S, Kawahara K: Detection of Epstein-Barr Virus Nuclear Antigen Leader Protein Expression in Various Human Cancers. In New Developments in Epstein-Barr Virus Research Chapter XI. Edited by Umar CS.: Nova Science Publishers; 2006:261-276.

48. Hildesheim A, Schiffman MH, Gravitt PE, Glass AG, Greer CE, Zhang T, Scott DR, Rush BB, Lawler P, Sherman ME: Persistence of type-specific human papillomavirus infection among cytologically normal women. J Infect Dis 1994, 169(2):235-240.

49. Castle PE, Schiffman M, Herrero R, Hildesheim A, Rodriguez AC, Bratti MC, Sherman ME, Wacholder S, Tarone R, Burk RD: A prospective study of age trends in cervical human papillomavirus acquisition and persistence in Guanacaste, Costa Rica. J Infect Dis 2005, 191(11):1808-1816.

50. Samoff E, Koumans EH, Markowitz LE, Sternberg M, Sawyer MK, Swan D, Papp JR, Black CM, Unger ER: Association of Chlamydia trachomatis with persistence of high-risk types of human papillomavirus in a cohort of female adolescents. Am J Epidemiol 2005, 162(7):668-675.

51. Shew ML, Fortenberry JD, Tu W, Juliar BE, Batteiger BE, Qadadri B, Brown DR: Association of condom use, sexual behaviors, and sexually transmitted infections with the duration of genital human papillomavirus infection among adolescent women. Arch Pediatr Adolesc Med 2006, 160(2):151-156.

52. Szkaradkiewicz A, Wal M, Kuch A, Pieta P: Human papillomavirus (HPV) and Epstein-Barr virus (EBV) cervical infections in women with normal and abnormal cytology. Pol J Microbiol 2004, 53(2):95-99.

53. Gordon SC, Moonka D, Brown KA, Rogers C, Huang MA, Bhatt N, Lamerato $\mathrm{L}$ : Risk for renal cell carcinoma in chronic hepatitis $C$ infection. Cancer Epidemiol Biomarkers Prev 2010, 19(4):1066-1073.

54. Salehipoor M, Khezri A, Behzad-Behbahani A, Geramizadeh B, Rahsaz M, Aghdaei M, Afrasiabi MA: Role of viruses in renal cell carcinoma. Saudi J Kidney Dis Transpl 2012, 23(1):53-57.

55. Shimakage M, Kawahara K, Harada S, Sasagawa T, Shinka T, Oka T: Expression of Epstein-Barr virus in renal cell carcinoma. Oncol Rep 2007, 18:41-46.

56. Parker A, Cerhan J, Lynch C, Leibovich B, Cantor K: History of urinary tract infection and risk of renal cell carcinoma. Am J Epidemiol 2004, 159:42-48.

57. American Cancer Society: Global Cancer Facts \& Figures. 2nd edition. Atlanta: American Cancer Society; 2011.

58. Fried B, Reddy A, Mayer D: Helminthes in human carcinogenesis. Cancer Lett 2011, 305:239-249

59. IARC: Monograph on the evaluation of carcinogenic risks to humans: schistosomes, liver flukes and Helicobacter pylori. Volume 61. WHO International Agency for Research on Cancer; 1994:9-175.

60. Bedwani R, Renganathan E, El Kwhsky F, Braga C, Abu Seif HH, Abul Azm T, Zaki A, Franceschi S, Boffetta P, La Vecchia C: Schistosomiasis and the risk of bladder cancer in Alexandria, Egypt. Br J Cancer 1998, 77(7):1186-1189.

61. Li N, Yang L, Zhang Y, Zhao P, Zheng T, Dai M: Human papillomavirus infection and bladder cancer risk: a meta-analysis. J Infect Dis 2011, 204(2):217-223.

62. Del Mistro A, Koss LG, Braunstein J, Bennett B, Saccomano G, Simons KM: Condyloma acuminata of the urinary bladder. Natural history, viral typing, and DNA content. Am J Surg Pathol 1988, 12(3):205-215.

63. Kitamura T, Yogo Y, Ueki T, Murakami S, Aso Y: Presence of human papillomavirus type 16 genome in bladder carcinoma in situ of a patient with mild immunodeficiency. Cancer Res 1988, 48(24 Pt 1):7207-7211.

64. Querci della Rovere G, Oliver RT, McCance DJ, Castro JE: Development of bladder tumor containing HPV type 11 DNA after renal transplantation. Br J Urol 1988, 62(1):36-38.

65. Maloney KE, Wiener JS, Walther PJ: Oncogenic human papillomaviruses are rarely associated with squamous cell carcinoma of the bladder: evaluation by differential polymerase chain reaction. J Urol 1994, 151(2):360-364. 
66. Barghi MR, Hajimohammadmehdiarbab A, Moghaddam SM, Kazemi B: Correlation between human papillomavirus infection and bladder transitional cell carcinoma. BMC Infect Dis 2005, 5:102.

67. Moonen PM, Bakkers JM, Kiemeney LA, Schalken JA, Melchers WJ, Witjes JA: Human papillomavirus DNA and p53 mutation analysis on bladder washes in relation to clinical outcome of bladder cancer. Eur Urol 2008, 53(4):858-859.

68. Frank GA, Zavalishina LE, Andreeva I: Immunohistochemical characteristics and a degree of differentiation of urinary bladder cancer. Arkh Patol 2002, 64(6):16-18.

69. Volgareva G, Trofimova O, Kuevda D, Zavalishina L, Golovina D, Andreeva Y, Ermilova V, Cheban N, Glazunova V, Matvejev V, Shipulina O, Frank G: HPV and urinary bladder cancer. Proceedings of the 25-th International Papillomavirus Conference. Malmo, Sweden; 2009:P-18.42.

70. Knöll A, Stoehr R, Jilg W, Hartmann A: Low frequency of human polyomavirus BKV and JCV DNA in urothelial carcinomas of the renal pelvis and renal cell carcinomas. Oncol Rep 2003, 10(2):487-491.

71. Abend JR, Jiang M, Imperiale MJ: BK virus and human cancer: innocent until proven guilty. Semin Cancer Biol 2009, 19(4):252-260.

72. Shen C, Wu J, Hsu C, Jou Y, Lin C, Wang M, Wu S, Chan M, Chiang M, Fang C, Chang D: The high incidence of JC virus infection in urothelial carcinoma tissue in Taiwan. J Med Virol 2011, 83(12):2191-2199.

73. Geetha D, Tong BC, Racusen L, Markowitz JS, Westra WH: Bladder carcinoma in a transplant recipient: evidence to implicate the BK human polyomavirus as a causal transforming agent. Transplantation 2002, 73(12):1933-1936.

doi:10.1186/1750-9378-7-35

Cite this article as: Alibek et al:: The role of infectious agents in urogenital cancers. Infectious Agents and Cancer 2012 7:35.

\section{Submit your next manuscript to BioMed Central and take full advantage of:}

- Convenient online submission

- Thorough peer review

- No space constraints or color figure charges

- Immediate publication on acceptance

- Inclusion in PubMed, CAS, Scopus and Google Scholar

- Research which is freely available for redistribution 